\title{
EL CONTENIDO EMOCIONAL DE LA COMUNICACIÓN EN LA SOCIEDAD DEL RIESGO. MICROANÁLISIS DEL DISCURSO
}

\author{
Eduardo Bericat Alastuey
}

Universidad de Málaga

\begin{abstract}
RESUMEN
Con este estudio, resultado de una investigación empírica de carácter cualitativo, se pretende poner de relieve el desinterés que las ciencias sociales, y particularmente la sociología, han mostrado por la dimensión emocional de la sociabilidad. Este desinterés, que puede comprenderse como expresión del ethos cultural de la propia modernidad, resulta científicamente insostenible. De ahí que en los últimos años haya emergido con fuerza una corriente de pensamiento, y un campo de estudio específico, la sociología de las emociones, que pretende llenar este vacío. La investigación, partiendo del papel clave que el proceso comunicativo juega en la constitución del orden social, tal y como sostienen tanto el interaccionismo simbólico como la teoría de sistemas de N. Luhmann, pretende mostrar las funciones sociales que cumplen los contenidos emocionales presentes en la comunicación. Aplicando microanálisis del discurso a noticias publicadas en prensa escrita revela, pese al principio de «neutralidad afectiva» que debería orientar la «información» periodística, la abundante presencia de contenidos emocionales, revelando, al mismo tiempo, la imposibilidad de una adecuada interpretación del significado y sentido de una noticia, o de cualquier expresión comunicativa, si no se tiene en cuenta su estructura emocional. En el artículo se presenta la estructura emocional de una noticia, "el relato de un accidente de coche», en la que su sentido comunicativo y social se construye con una cadena de horror, de vergüenza y de preocupación. Aplicando al análisis de este artículo la metodología desarrollada por Thomas J. Scheff, que denomina part/whole analysis, se establecen conexiones entre esta cadena y la estructura vital de la sociedad posmoderna considerada en tanto sociedad del riesgo. Se sostiene que la sociedad contemporánea ya no puede basar su legitimidad en las metas, "positivas", que sostuvieron y animaron a la sociedad moderna. En la sociedad del riesgo la legitimidad se sostiene no por la búsqueda de bienes, sino por la evitación de males, y en este nuevo modo de legitimidad, la cadena emocional aquí descrita, horror-vergüenza-preocupación, cumple una función social imprescindible.
\end{abstract}




\section{INTRODUCCIÓN}

El abandono en que han mantenido las ciencias sociales la dimensión emocional del ser humano no sólo causa cierta extrañeza, sino que además incita a la sospecha. Bien es cierto que este abandono se consuma con la consagración del positivismo ingenuo, pues, como es sabido, al menos en el ámbito de la sociología, ningún autor de los considerados clásicos: G. Simmel, M. Weber, E. Durkheim, F. Tönnies, A. de Tocqueville, A. Comte y otros, olvidó incluir en sus perspectivas sociales el componente emocional. Cierto es también que el tratamiento otorgado por estos autores al ámbito de las emociones fue descriptivamente burdo y teóricamente pobre. El caso más sintomático de esta actitud científica corresponde a la tipología de la acción social elaborada por $\mathrm{M}$. Weber, en la que apenas se esbozan algunos rasgos de la denominada acción emocional, erróneamente identificada con lo que cabría calificar como acción pasional. Un tipo de conducta de tan singulares características resulta inservible para sustentar ninguna teoría de la acción social. Con la excepción de ciertas escuelas psicológicas, cuya circunscripción al cerrado mundo de la subjetividad del individuo aislado les enfrenta ineluctablemente a la realidad emocional del sujeto, el resto de las ciencias sociales, sea la economía, el derecho, la historia, la comunicación, la antropología, han prescindido radicalmente de la emoción. Para ser exactos, avanzando en la sospecha, podría decirse que han elaborado su cuerpo teórico no ya sin emociones, sino contra las emociones.

Este proceso, por el que las ciencias se construyen contra las emociones, es desvelado ideológicamente en el campo de la economía por A. O. Hirschman. En las páginas de Las pasiones y los intereses, Hirschman muestra cómo una nueva categoría, los intereses, va desplazando conforme avanza la modernidad a lo que anteriormente se calificaba como pasiones. Esta transformación terminológica es síntoma, para el autor, de un cambio de época: «En el Renacimiento surgió la sensación, convertida en firme convicción durante el siglo XVII, de que ya no se podía confiar a la filosofía moralizadora y a los preceptos religiosos la restricción de las pasiones destructivas de los hombres» (Hirschman, 1999: 39). Se pensó entonces domar las pasiones, aquellas consideradas destructivas, con el concurso de otras pasiones que compensaran a las primeras: «En los numerosos tratados de las pasiones que aparecieron en el siglo XVII no se encuentra ningún tipo de cambio en la valoración de la avaricia como "la más abyecta de todas"... Pero una vez la obtención de dinero llevó la etiqueta de "intereses" y volvió a penetrar con este disfraz en la competencia con las demás pasiones, fue súbitamente aclamada y aun se le encomendó la tarea de reprimir pasiones..." (Hirschman, 1999: 63). En principio, el concepto de intereses refería un conjunto amplio de deseos, emociones y preocupaciones humanas, pero finalmente se redujo su significado al beneficio material. Se extendió el convencimiento de que el interés participaba de la mejor naturaleza de cada una de las clásicas fuentes de la motivación humana, la pasión y la razón. El interés se consideró desde entonces «como la pasión del amor propio 
enaltecida y limitada por la razón, y como la razón dirigida y vivificada por la pasión» (Hirschman, 1999: 66).

En el ámbito de la sociología, el estudio de la represión de las emociones, en tanto proyecto íntimo de la modernidad, fue realizado por Norbert Elias con una ingeniosa investigación sociohistórica publicada bajo el título El proceso de la civilización. A través del análisis de diversos manuales de buena conducta, publicados a partir del Renacimiento, Elias descubre un proceso de refinamiento en los modales, o civilidad, bajo el que se esconde una definida pauta de evolución en la estructura emotiva de las sociedades occidentales. Al estudiar los modales en la mesa; las conductas decorosas a la hora de realizar necesidades naturales, como sonarse la nariz, escupir u orinar; al tratar las actitudes ante la desnudez de los cuerpos y ante las relaciones sexuales entre hombres y mujeres; o, finalmente, cuando se considera la agresividad, se observa siempre un avance del control emocional, un paso desde el control externo de la conducta al autocontrol. En este proceso, el tenedor, el pañuelo y el pijama, aparecidos históricamente en torno al siglo XVII, y usados al inicio por las clases cortesanas, son al tiempo instrumentos y síntomas de la transformación de la estructura emotiva introducida en la modernidad frente a la tradición medieval.

Las pulsiones corporales, sean escatológicas, sexuales o agresivas, son dominadas, limitadas, expulsadas de la sociedad civilizada por medio de una modificación, al alza, del umbral del sentimiento de vergüenza. Elias, sin citar esta emoción, la refiere en muchas de sus observaciones. Descubre que la producción del asco, de la repugnancia o del sentimiento de pudor es el objetivo principal de estos manuales de buena conducta. Estas emociones, cuyo desarrollo sociogenético estudia Elias, son las que operan como inhibidores de las conductas más asociadas al cuerpo, sustento próximo de las pasiones. Según el principio compensatorio descrito por Hirschman, sólo una pasión podría contrarrestar las pasiones. En la economía, la avaricia convertida en interés. En la sociedad, la vergüenza convertida en civilidad.

Si el proyecto de la modernidad se identifica en negativo con el destierro de las emociones, con su represión y encubrimiento, la sospecha acerca del sesgo antiemocional de las ciencias sociales queda resuelta en gran parte. La estructura vital de la sociedad moderna requería una cambio en su estructura emotiva. Así, el individualismo que caracteriza a la modernidad, su mito fundacional, sólo puede ser mantenido, de acuerdo con la teoría de Th. J. Scheff, reprimiendo la conciencia de las dos emociones sociales por antonomasia, la vergüenza y el orgullo. En opinión de este autor, ambas emociones señalan a los individuos el estado de un determinado vínculo social. La vergüenza indica una amenaza o una ruptura de ese vínculo; bien una distancia social excesiva (isolation), bien una ausencia de distancia social (engulfment). El orgullo indica un vínculo social seguro (secure bond), aquel que nos une a los otros desde el respeto a la individualidad de nuestro ser. Reconocer la vergüenza o el orgullo, que se producen en nosotros por la imagen que tienen o creemos que tienen 
los otros de nuestra persona, equivale a poner de manifiesto el vínculo social, la necesidad que de ellos tenemos, la imposibilidad del aislamiento. Nos produce vergüenza tener vergüenza y sentir orgullo. No podemos reconocer nuestra propia vergüenza y nuestro propio orgullo porque en tal caso el mito individualista de la modernidad, y la modernidad misma, quedarían al descubierto, explícitamente cuestionados (Scheff, 1990).

Si esta estructura emotiva de autocontrol está íntimamente vinculada al programa moderno, a su estructura vital, se explica el abandono al que nos referíamos. Tan grave y deletérea es para las ciencias sociales la omisión del componente emocional, tan evidente es su presencia, que no podía deberse a un mero despiste o a un inexplicado olvido, sino a una sólida y fundamental constricción sistémica, a un mandato que, en aparente paradoja, alcanza también a las ciencias responsables del estudio del sistema social. Esta ausencia, por último, no resulta menos sospechosa en las ciencias de la comunicación, así como en aquellas teorías sociales que conciben el orden social como producto de la interacción comunicativa. A este respecto, es de resaltar el escaso interés que mostró G. H. Mead por la dimensión emotiva de la interacción social (MacKinnon, 1994).

La investigación que se presenta en este artículo ${ }^{1}$, inserta en la línea del reciente pero prometedor desarrollo de la sociología de las emociones, parte de un conjunto de microanálisis empíricos del contenido emocional de unidades expresivas publicadas en medios públicos de comunicación. En estos análisis se pretende desvelar las estructuras emocionales de las expresiones comunicativas con el objeto de, posteriormente, relacionar estas estructuras emotivas de la comunicación con las estructuras vitales características de las sociedades posmodernas.

\section{EMOCIONES, COMUNICACIONES Y SISTEMA SOCIAL}

El advenimiento de la sociedad de la infocomunicación ha tenido, entre otros efectos, la virtud de hacer evidente por sí mismo el papel clave que la comunicación juega en la constitución del orden/caos social (Bericat, 1996). Aquello que sólo con dificultad y perspicacia puede intuirse en el plano de singulares interacciones comunicativas entre dos sujetos individuales, y que puso de manifiesto desde sus orígenes el interaccionismo simbólico ${ }^{2}$, esto es, que el orden/caos es construido por y desde la comunicación, se muestra clara y distintamente, como a través de una enorme lupa, cuando se consideran los sistemas sociales en su conjunto.

${ }^{1}$ La investigación se realizó en el Departamento de Sociología de la Universidad de California, en Santa Bárbara, bajo la dirección del profesor Thomas J. Scheff.

2 Según J. Carabaña y E. Lamo de Espinosa, «el interaccionismo simbólico, especialmente en su versión meadiana, tiene la enorme relevancia de haber sido la primera teoría comunicativa de la sociedad» (Carabaña y Lamo de Espinosa, 1978: 317). 
La obra de Niklas Luhmann explicita en el plano de la metateoría social este nuevo e inexcusable reconocimiento. Los sistemas sociales dejan de estar compuestos por individuos y dejan de ser considerados como sistemas de acción. Son sistemas autopoiéticos que se autoproducen a sí mismos de forma autorreferencial mediante un proceso de autoobservación de diferencias que solamente puede desenvolverse en un horizonte de comunicaciones. La principal de estas diferencias es la diferencia sistema-entorno. Las comunicaciones, desde esta perspectiva, ocupan el centro de la escena metateórica, pues son consideradas como las unidades básicas de todo sistema social, aquello por lo que adquieren tanto su forma como su sentido.

Las teorías tradicionales de la comunicación social, así como algunas teorías sociales de la cultura, concebían el ámbito comunicacional como «enfrentado a» o como algo "distinto de» las estructuras sociales, único ámbito al que se le otorgaba auténtico estatuto de realidad. Desde estas perspectivas la cultura se concibe, a lo sumo, como un subsistema del sistema social general; y los medios masivos de comunicación, propiamente dichos, como algo exterior que interactúa con la estructura social. Es en este contexto donde cobran sentido las argumentaciones típicas y tópicas con respecto, por ejemplo, al papel de los medios de comunicación en torno al problema de la violencia. Los medios pueden ser perfectamente culpabilizados y diabolizados en tanto se consideran externos al sistema social, bondadoso por naturaleza (sic). Pero si la comunicación, clave de la autorreferencia, determina la producción del sistema, ya no podremos seguir concibiéndola ni como algo exterior ni siquiera como un subsistema específico, por muy importante que éste sea.

Una nueva perspectiva de análisis es necesaria a la hora de considerar tanto la comunicación como sus medios de difusión masiva. La metáfora de la «transmisión", según Luhmann, es inservible por varias razones. En primer lugar, porque «sugiere que el emisor transmite algo que es recibido por el receptor. Éste no es el caso, simplemente porque el emisor no da nada, en el sentido de que pierda él algo. La metafórica del poseer, tener, dar y recibir no sirve para comprender la comunicación». En segundo lugar, «la metáfora de la transmisión coloca lo esencial de la comunicación en el acto de comunicación». "El acto de comunicar, sin embargo, no es más que una propuesta de selección, una sugerencia. Sólo cuando se retoma esta sugerencia, cuando se procesa el estímulo, se genera la comunicación.» En tercer lugar, «exagera la identidad de lo que se "transmite". Al recurrir a ella nos seduce la idea de que la información que se transmite es la misma para el emisor que para el receptor» (Luhmann, 1995: 139-140).

Luhmann concibe la comunicación, en el marco de su teoría general de la contingencia, como una triple selección, como la unidad de tres actos selectivos: información, expresión comunicativa y comprensión. Cada uno de ellos implica una diferencia. La información, equivalente al contenido de lo que se comunica, es producto de una selección, la percepción selectiva de una diferencia. Pero la información por sí misma no produce comunicación, pues la 
información ha de ser expresada, y esto, en sí mismo, implica otra selección, marca una nueva diferencia. Por último, la expresión comunicativa ha de ser comprendida, comprendida en tanto diferencia entre información y comunicación, esto es, comprendida desde la propia lógica comunicacional, que reconoce tanto la selección informativa como la expresiva, así como la diferencia entre ambas. Para Luhmann, la comunicación, en sentido estricto, es la unidad de estos tres procesos $\mathrm{u}$ actos, informativo, expresivo y comprensivo, unidad que sólo es posible en tanto proceso autorreferencial.

La comunicación, así entendida, como proceso productor del sistema mediante selecciones autorreferentes, siempre "toma algo del auténtico horizonte referencial constituido por ella misma, y deja aparte lo otro» (Luhmann, 1995: 140). Información, expresión comunicativa y comprensión cierran y completan el fenómeno comunicativo. Más allá de sí misma, la comunicación contiene otras dos selecciones, una antecedente y otra consecuente. La antecedente es la atención selectiva necesaria para que el proceso de comunicación pueda tener lugar. La consecuente se deriva del carácter propositivo de toda comunicación, esto es, de la aceptación o del rechazo por parte del receptor del específico sentido de lo comunicado, lo que podrá o no constituir una premisa para su conducta (Luhmann, 1995: 147). Una comunicación comprendida (si no es comprendida no sería tal) puede ser, sin embargo, aceptada o rechazada, si bien la mera comprensión o entendimiento modifica ya radicalmente el estado del receptor: en adelante, éste ya no podrá prescindir de lo comunicado, bien sea para aceptar su sentido, bien para rechazarlo.

Esta selección de aceptación o rechazo del sentido de lo comunicado establece un vínculo pragmático con las actividades del sistema, la acción se modifica desde la propia autorreferencia evocada por la comunicación. Un vínculo entre comunicación y actividad también puede detectarse en la metateoría comunicacional de Habermas, aunque en este caso el vínculo queda enmarcado, y por tanto limitado analíticamente, en una propuesta de sistema en tanto comunidad moral establecida por los interactuantes en el marco de un modelo dialógico de comunicación pura (Habermas, 1994a). Otras propuestas que vinculan comunicación y acción o actividad social pueden encontrarse entre los pragmatistas, por ejemplo en John Dewey, para quien la comunicación, lejos de los modelos individualistas, transmisores y solipsistas, lleva directamente a la cooperación. «El fracaso de la comprensión — nos dice Deweysupone el fracaso del acuerdo para la acción» (Dewey, 1958: 149). Pero la comunicación, para Dewey, no es sólo un instrumento: «La comunicación es finalista así como también instrumental. Como medio establece la cooperación, la dominación y el orden. Como fin, la vivencia compartida es el mayor de los bienes humanos» (Dewey, 1958: 167).

Más allá de las sustanciales diferencias que separan a estos tres autores, los tres comparten un mismo interés por la comunicación en tanto constituyente del orden/caos social, de la identidad y esencia del sistema, de su realidad, no en tanto mera potencia de ser, sino en tanto existencia actual. Comparten, asi- 
mismo, la admiración por el lenguaje natural, al que tanto Dewey como Luhmann, en los textos que comentamos, hacen referencia como the tools of tools. También comparten, por último, una perspectiva de la comunicación, del lenguaje y de la conciencia que deja fuera de foco sus lugares y contenidos típicos, identificando así conciencia y cognición, comunicación y conocimiento, lenguaje y significado. Ello ha impedido, entre otras cosas, el reconocimiento de las emociones como otro lugar de la conciencia y otro contenido de la comunicación imprescindible para desentrañar su sentido. Ello ha impedido, también, el análisis de los componentes emocionales de la comunicación y, por ende, del papel que estos componentes pudieran tener en la constitución del orden social.

Muchos han sido los pensadores y científicos sociales, entre ellos K. Popper, J. Habermas o T. Parsons, que han señalado de diversas maneras el hecho clave de que la realidad humana está constituida en y por la intersección de tres mundos: el mundo natural, el mundo social y el mundo personal. Siendo esto así, estos tres mundos han de tener su reflejo en el ámbito de la comunicación, reflejo que señala Habermas al hablar de las propias capacidades del lenguaje. Para Habermas, el lenguaje sirve para expresar las vivencias interiores de un hablante, es decir, sirve para referir y expresar su mundo personal. En el programa moral de Habermas, la condición de legitimidad de lo expresado en este ámbito es la autenticidad. El lenguaje también es capaz de reflejar el mundo social en tanto refiere normas y valores de la acción que vinculan en tanto expectativas al hablante con el oyente. La condición de legitimidad en este ámbito, según Habermas, es la rectitud. Por último, el lenguaje es un instrumento con el que el ser humano se representa el mundo natural, un objeto que existe fuera de él. En este caso, la condición de legitimidad viene determinada por el principio de verdad (Habermas, 1994b).

Si aceptamos esta triple potencialidad del lenguaje, y establecemos una fundamental homología entre comunicación y conciencia, tanto en la comunicación social como en la conciencia individual podrán hallarse rastros de los tres mundos citados. La homología entre conciencia y comunicación puede sostenerse, siguiendo a E. Husserl, atendiendo al carácter intencional de la conciencia, es decir, atendiendo al hecho de que la conciencia es siempre conciencia de algo, o sea, que establece comunicaciones con lo otro. Los tres mundos aparecen en la conciencia como tres lugares distintos del ser. Como conciencia de un exterior dado en tanto objeto (mundo natural), como conciencia de un exterior dado en tanto sujeto (mundo social) y como conciencia de un interior dado en tanto sujeto-objeto (mundo personal). En el plano individual, del mismo modo que en el social, y siguiendo a Luhmann, el yo, a mi modo de ver un yo trascendental, se constituye en tanto diferencia/unidad expresada con lo otro (mundo natural), los otros (mundo social) y el yo mismo (mundo personal).

Esta triple constitución de todo sistema, sea individual o social, deja sus marcas en el lenguaje, en la conciencia y en la comunicación, señalando así sus 
tres contenidos o componentes básicos: a) cognitivos, b) valorativos, y c) emotivos. El componente cognitivo, con su correspondiente principio de verdad objetiva, se orienta a la aprehensión de todo aquello considerado objeto externo (mundo natural). El componente valorativo, con su correspondiente principio de rectitud, se orienta a la aprehensión de todo aquello considerado sujeto externo (mundo social). El componente emotivo, con su correspondiente principio de autenticidad, se orienta a la aprehensión de todo aquello considerado sujeto-objeto interno (mundo personal).

Cuando las teorías de la comunicación pervierten el significado del término "conciencia» identificando conciencia a cognición, como es práctica habitual desde los paradigmas meramente «informativos», y conciben los componentes valorativos y emotivos como sustancia extraña, como «ruido» ajeno a la "pura" comunicación, se incapacitan ab initio para comprender cualquier comunicación que pueda considerarse humana. Si bien esta mutilación ha afectado a los componentes valorativos, no cabe duda que ha sido total para los componentes afectivos. Aquí, de nuevo, puede observarse cómo la vida y sus mensajes van por un lado, mientras la ciencia y sus mensajes se orientan radicalmente hacia otro. No hay comunicación humana que no contenga en su seno una estructura de componentes cognitivos, valorativos y emotivos. Sin embargo, las ciencias de la comunicación, impasibles, siguen haciendo caso omiso de todo lo que no sea cognición. La siguiente declaración de Habermas: «... en el acto del habla aceptable siempre hacen simultáneamente ${ }^{3}$ presencia fragmentos de la naturaleza externa, de la sociedad y de la naturaleza interna» (Habermas, 1994b: 367), que en sí misma constituye la base para un proyecto hermenéutico, no ha encontrado el menor eco.

En suma, si las comunicaciones constituyen las unidades autoproductoras de los sistemas sociales, y si las comunicaciones contienen rastros de los tres mundos que se funden en la realidad humana y social, resultará legítima la empresa de investigar, primero, el papel que cumple el componente emocional en el sentido de las comunicaciones y, segundo, por derivación, el papel que cumplen las emociones comunicadas en la estática y en la dinámica del orden social.

\section{EL RELATO DE UN ACCIDENTE DE COCHE}

En el marco del contexto metateórico esbozado en los párrafos precedentes, presentamos en este epígrafe los resultados de aplicar a un artículo de prensa un análisis microscópico del discurso. El artículo que se comenta, «el relato de un accidente de coche», publicado en Los Angeles Times el día 7 de mayo de 1998, es uno de los casi cien artículos analizados en la investigación. Estos análisis tenían por objeto, en primer término, revelar los contenidos emocionales

\footnotetext{
3 La cursiva es nuestra.
} 
presentes en las noticias periodísticas. En segundo término, establecer pautas de relación entre los componentes emocionales de cada artículo, con el fin de descubrir y tipificar diversas cadenas o estructuras emocionales. En tercer término, estudiar las conexiones entre estas estructuras emocionales, el sentido de las expresiones comunicativas analizadas y el sistema social.

La selección de "un» artículo se debe a nuestro interés por mostrar que una lectura atenta de cualquier expresión comunicativa, incluso de una noticia de un periódico considerado "serio», cuya deontología profesional ofrece una imagen de mero transmisor de «informaciones objetivas», revela un intenso y rico mundo emocional. De hecho, sorprende la cantidad, variedad e intensidad emocional presente en este y en casi todos los artículos de prensa analizados. Sorprende porque cuando se habla de emociones en la comunicación, espontáneamente pensamos en las telecomedias, en los reality shows o en la prensa del corazón, dando por sentado el hecho de que en un noticiario televisivo o en un periódico serio las emociones no cumplen ninguna función importante. Aquí el error básico consiste en no tener en cuenta que cada medio tiene unos estándares o normas expresivas propios que determinan el grado en que las emociones pueden manifestarse, esto es, expresarse abiertamente o, por el contrario, permanecer ocultas.

La selección de "este» artículo concreto se debe, en primer término, a que su estructura emocional aparece, con diversas variantes, en muchos otros artículos de prensa, por lo que puede considerarse una especie de tipo ideal, en el sentido weberiano del término. El análisis de este tipo de estructura emotiva, en segundo lugar, nos llevará a establecer conexiones con la estructura social en su conjunto, permitiendo así entender el verdadero sentido de lo comunicado en la noticia, esto es, comprender la comunicación que porta el relato en cuanto unidad de, en términos luhmannianos, información, expresión y comprensión. Por tanto, sirve también para demostrar que no puede existir una hermenéutica completa y correcta del discurso si no se tienen en cuenta tanto los contenidos como la lógica emocional que incorpora.

La metodología aplicada al análisis del artículo está directamente inspirada en el part/whole analysis desarrollado por Thomas J. Scheff (Scheff, 1997). Esta metodología de integración macro-micro se caracteriza por su interés en vincular las partes más pequeñas de la interacción social con los todos más grandes de la estructura social. Desde el convencimiento de que para conocer el todo es necesario conocer estas partes ínfimas, así como desde el convencimiento de la complejidad de estas partes, postula un estudio microscópico de la realidad social que puede y debe ser integrado en la propia comprensión del sistema social en su conjunto. En este epígrafe se aplica el análisis microscópico del discurso a una expresión comunicativa, un artículo de prensa, en tanto realidad autónoma y autosuficiente, en tanto presencia en el universo comunicacional. En el último epígrafe se reflexiona sobre los vínculos entre este ínfimo evento comunicativo y el sistema social en su conjunto. Este objetivo es al que se refiere Edgar Morin cuando afirma: «mientras que habitualmente se 
tiende a disociar estos dos conceptos antagónicos, evento y sistema, es preciso que, por el contrario, intentemos concebir de qué manera están indisolublemente unidos» (Morin, 1984: 140). Objetivo básico del part/whole analysis aquí aplicado.

Antes, sin embargo, es necesario analizar el contenido emocional del artículo, así como el contenido causal del mismo, para lo que es preciso una atenta, completa y previa lectura de esta expresión comunicativa, incluida en el Anexo.

\section{a) EL CONTENIDO EMOCIONAL DEL RELATO: HORROR, VERGÜENZA Y PREOCUPACIÓN}

En Estados Unidos, en España, así como en otros países, se extiende entre la juventud la costumbre de designar, entre los componentes de un grupo de amigos, al responsable de conducir el vehículo que transportará al grupo durante su salida nocturna. La designación como conductor implica la prohibición de cualquier ingesta de alcohol, pues con esta práctica lo que pretende evitarse es la peligrosa fórmula de «alcohol+automóvil», que ha mostrado ya, sobradamente, su eficacia fatal. Un grupo de amigos salió a divertirse por la noche, pero con tan mala fortuna que, al tomar una curva muy pronunciada, el coche se salió de la calzada, dando varias vueltas de campana. Las consecuencias del accidente fueron fatales. Un joven resultó muerto y otros dos sufrieron gravísimas lesiones cerebrales. El conductor salió ileso. El conductor no había bebido. Era el primer día que conducía ese automóvil, y conducía por encima del límite de velocidad. El joven muerto era su amigo. También eran amigas quienes sufrieron las gravísimas lesiones cerebrales.

El hecho conmocionó de inmediato a toda la comunidad. Alguno de sus hijos había muerto. Alguno de sus hijos, quizás el responsable, seguía vivo. Las madres de los afectados llevaron a juicio al amigo de sus hijos, y se desencadenó una intensa batalla legal. La comunidad no quedó al margen, sino que participó intensamente en esta batalla desde el principio. Aunque la comunidad comulgó al unísono en el dolor y la desgracia que les había traído el accidente de coche, la fractura de la comunidad se hizo pronto evidente al considerar el problema de culpabilidad que planteaba el caso. La división social y el disenso comunitario permanecieron vivos durante todo el transcurso del proceso. La noticia objeto del análisis corresponde al día en que el juez emitió el veredicto final.

\section{El horror}

Del análisis descriptivo del contenido emocional de los artículos investigados, así como del análisis tipológico de sus estructuras, se deducen dos conclu- 
siones importantes. La primera refiere el hecho de que, en términos generales, las noticias contienen mayor carga emocional al principio de los artículos, cediendo en intensidad conforme se avanza hacia el final de los mismos. Esta carga emocional pone de manifiesto, en el orden de la comunicación, lo que ya S. Freud indicó en el tratamiento de la ansiedad, la función de señal que esta emoción cumplía. La ansiedad indica al yo, le anticipa, algún peligro externo o interno. El lector de una supuesta noticia redactada en puro lenguaje cognitivo carecería de adecuadas indicaciones para valorar su importancia y, por ende, disminuiría su interés para seguir «informándose». Esta función de señal de las cargas emocionales, de otra parte, constituye el enlace que posibilita la sintonía en el foco de atención entre la expresión comunicativa y su receptor. Un mismo foco de atención, como vimos en los comentarios de Luhmann, no es parte de la unidad comunicativa, pero sí es condición necesaria, aunque previa, de la comunicación.

La segunda conclusión refiere el hecho de que en gran parte de las noticias analizadas está presente, directa o metafóricamente, la muerte ${ }^{4}$. En la escala de ansiedad elaborada por L. A. Gottschalk se incluyen, como dos de sus ámbitos, tanto las referencias del texto a la muerte, al morir y a las amenazas de muerte, como a mutilaciones, heridas, daños físicos o amenazas de tales (Gottschalk y Gleser, 1969). El relato del accidente de coche no es una excepción. Incluye al inicio una gran carga emocional, carga que está vinculada con la muerte y la mutilación física. El mismo titular, en su título, hace alusión al /fatal accidente/. El subtítulo indica asimismo que /murió/ un joven y que /otros dos resultaron gravemente heridos/. Al inicio del cuerpo de la noticia abundan las referencias: /murió/ un compañero de clase $(1)^{5}$; dejó a otros dos con /graves lesiones cerebrales/ (1); / «Sabe que ha sido a sus amigos a quienes hirió»/ (4); el vehículo se salió de una curva /arrojando ocho adolescentes sobre la calzada/ (5); /En el accidente murió Donny Bridgman/ (7); /Amanda Arthur, de 18 años, entró en coma/ (7); Arthur padece una /lesión cerebral posiblemente irreversible/ (7); otro estudiante se está recuperando de una /lesión cerebral/ (7).

Pese a todo, la referencia a la muerte no determina con exactitud el primer eslabón de la cadena emocional del relato; es más bien el catalizador del horror, su primer elemento. El mismo texto incluye la definición emocional explícita del hecho que da lugar al relato. La abogada defensora de Jason Rausch, el joven conductor, aludiendo a la orden del juez que obliga al inculpado a contar su historia a otros jóvenes en centros escolares, dice: / Cada vez que se dirija a un grupo, tendrá que hacerse de acero para rememorar estos acontecimientos, que son horrorosos ${ }^{6}{ }_{\text {} /} /(22)$. El texto no dice que alguien sintió horror, como corresponde a cualquier emoción, sino que los acontecimientos

${ }^{4}$ La presencia de la muerte también puede constatarse en los noticiarios televisivos actuales.

5 Comentario sobre la notación utilizada: el número entre paréntesis corresponde al párrafo de la noticia. Las citas van encerradas entre dos barras /.../; cuando en el interior de ellas aparecen comillas, se trata de una cita incluida por el periodista en el propio texto.

${ }^{6}$ La cursiva, así como todas las que aparecen posteriormente, son nuestras. 
«Son" horrorosos, indicando por medio de esta supuesta objetividad el consenso colectivo en la definición emocional.

Desde nuestra perspectiva, un acontecimiento puede calificarse de horroroso cuando concurren simultáneamente tres emociones. La primera está relacionada con la ruptura súbita del orden, sea natural, social o personal. Está relacionada, por tanto, con la ruptura de las expectativas, tal y como se puso de manifiesto en las reacciones emocionales provocadas en los experimentos de ruptura que llevó a cabo H. Garfinkel. Como indicó este autor, la descomposición del orden produce, en el plano social, una súbita pérdida de confianza. Sorpresa y tedio indican el estado del orden. La normalidad produce tedio; los acontecimientos extraordinarios o inesperados, sorpresa. El relato cuenta la historia de un "accidente», esto es, un acontecimiento que por definición está más allá del funcionamiento normal o esperado de las cosas. El horror, por este motivo, va siempre asociado a un shock emocional.

Pero la ruptura del orden no es suficiente para producir horror, tan sólo puede producir sorpresa. Esta sorpresa debe venir acompañada de vergüenza. Entonces el acontecimiento funciona como un espejo donde se refleja una imagen desagradable del «nosotros». El acontecimiento nos resulta insoportable, moralmente insoportable. En este sentido, el horror es una forma de autoprotesta. En nuestro relato, un amigo mata a otro amigo, hecho que indica la reflexividad social del daño, esto es, se trata de una especie de suicidio social o fratricida. Si ellos se han matado, algo falla en nuestra comunidad, puede pensarse.

Por último, el horror viene acompañado de un miedo intenso. Miedo que en el horror se nutre, en primer lugar, de la propia ruptura del orden, en tanto horror vacui, tal como lo expresara Nietzsche, o en tanto miedo al cambio, siguiendo la hipótesis de acción tradicional en Weber. Miedo, en segundo lugar, a nosotros mismos, que es el miedo expresado en la vergüenza. Y, en tercer lugar, miedo al miedo, que se expresa en el puro miedo a la muerte. Este horror, compuesto de sorpresa, vergüenza y miedo, se manifiesta también en el terror del «terrorismo», en los "escándalos públicos», así como en la recientemente denominada "alarma social». Los medios de comunicación, en la actualidad, establecen su primer enlace comunicativo autorreferente por medio del horror. El horror constituye una conciencia, cumple una función de señal, capta la atención forzando y sincronizando espacial y temporalmente la mirada de todos. E. Durkheim supuso ya este mecanismo al analizar los efectos sociales del asesinato.

\section{La vergüenza}

Tanto la ardiente batalla legal como el amargo e intenso debate desatado en la comunidad, a los que se refiere nuestro relato del accidente de coche, expresar el dilema social de la atribución de culpa o de vergüenza. El titular de 
la noticia anuncia la resolución legal de este dilema: Jason Rausch, el joven conductor, no irá a la cárcel. No se le puede declarar culpable de la muerte de su amigo. Sin embargo, aquí no acaba la historia, pues todavía queda por considerar la resolución social del caso. Ya en 1910, M. Weber citó la opinión de Anton Merger señalando «que en el Estado del futuro el cometido de la prensa sería precisamente sacar a la luz pública aquellos asuntos que no puedan ser sometidos a los tribunales de justicia» (Weber, 92: 253). Esto es lo que hace nuestro artículo. Al mismo tiempo que niega la culpa, afirma y proyecta la vergüenza sobre el conductor; aunque tal emoción ni tan siquiera sea mencionada una sola vez en toda la noticia. La presencia de este sentimiento es clave para comprender el sentido de la expresión comunicativa y, sin embargo, aparece como una emoción sin nombre. Por este motivo, para reconocer la vergüenza en el texto, que posiblemente habrá pasado desapercibida al lector, es importante indicar antes su origen, sus manifestaciones típicas y su naturaleza fundamental ${ }^{7}$.

Para ello conviene establecer una importante distinción previa, aunque no siempre evidente, entre culpa y vergüenza. La culpa, desde nuestro punto de vista, forma parte de la dimensión interactiva de la sociabilidad. La vergüenza, por el contrario, opera sobre la dimensión intercomunicativa de la sociabilidad. Esta distinción puede encontrarse en el relato bíblico. La muerte de Abel a manos de Caín constituye el paradigma del modelo de culpa, pues Caín "hace» algo sobre su hermano. Desde una posición de poder, consciente de sus actos, le golpea con la quijada hasta su muerte, contraviniendo así la ley. La huida de Caín, por temor a una reacción del cuerpo social, es típica de este modelo de culpa. La respuesta social a un acto culpable es la restitución operada en la venganza, la Ley del Talión, del ojo por ojo. Si un miembro hace algo, la sociedad restituye el daño haciéndole algo. Se trata de un juego de actividad y, por tanto, de un juego de poder a poder, donde los sujetos están dados en tanto objetos. Caín no consideró a Abel en tanto sujeto, sino en tanto objeto molesto a sus fines. La Ley, ciega en su representación, trata al acusado como algo ajeno a la comunidad, como un objeto.

El modelo de la vergüenza, por el contrario, se expresa en el relato de la expulsión de Adán y Eva del Paraíso Terrenal. Eva también hizo algo, comió de la fruta prohibida, pero este acto no es una actividad, propiamente hablando; es tan sólo un símbolo, una acción cuya única consecuencia es la ruptura de una norma social que se ha dado a sí mismo el grupo, y que significaba, precisamente, la unidad y comunión con el grupo. Comiendo de la fruta prohibida, Eva osó marcar esta "distancia social», y por ello ambos fueron expulsados de esta acogedora placenta que es la comunidad. La respuesta de Adán y Eva no fue la huida, sino el pudor y la vergüenza, la conciencia de que habían vulnerado la norma social y que como tales eran observados. La vivencia compartida,

7 En la conceptualización de la vergüenza seguimos la amplísima obra desarrollada por Thomas J. Scheff, así como la realizada por Suzanne M. Retzinger. 
producto de la comunicación, y el mayor de los bienes humanos, como dijera Dewey, ya no se obtendrá de ahora en adelante sino a costa de un gran esfuerzo. Aquí el castigo no es venganza, ni la respuesta social tiende a la restitución. Sólo la restauración del vínculo social roto permite la reintegración a la comunidad, algo que se obtiene no mediante un actividad, sino mediante un acto comunicativo: la solicitud de perdón.

Esta dimensión comunicativa de la vergüenza se hace evidente en la concepción del "yo social» de Charles Horton Cooley, a quien el profesor Scheff considera el profeta de la función de la vergüenza en la conducta humana (Scheff, 1990: 81). Cooley, refiriéndose al yo social, en una cita ya clásica, señaló lo siguiente: "Una autoidea de este tipo (el yo social) tiene tres elementos principales: la imaginación de cómo aparecemos ante la otra persona; la imaginación del juicio de ésta sobre tal apariencia, y una especie de autosentimiento, como orgullo o mortificación» (Cooley, 1902: 152). Interesa notar de nuevo que el yo social de Cooley, en tanto conciencia de sí mismo, se nutre también de tres componentes: el cognitivo (imaginar la apariencia), el evaluativo (imaginar el juicio) y el emotivo (autosentimiento). Interesa notar, también, que una concepción del yo social que sólo contara con los dos primeros componentes sería incapaz de explicar por qué el individuo se somete al imperativo de unas «meras» imaginaciones. Sólo el placer del orgullo, así como el intenso dolor de la vergüenza (Cooley la denomina precisamente «mortificación»), pueden transformar lo cognitivo y lo evaluativo en condicionamiento eficaz de la conducta del yo (Scheff, 1990). El origen tanto del orgullo como de la vergüenza está vinculado, por tanto, a la interiorización de la mirada evaluativa del otro. Interesa notar, en tercer término, que en la formación de este yo social no interviene una actividad, pues el otro nada hace, sino una amenaza de comunicación, una posible crítica. El yo interioriza esta crítica para mantener una adecuada distancia social. La vergüenza señala, por tanto, el estado del vínculo social.

El sentimiento de vergüenza, más allá del restrictivo uso vernáculo del término, ha de considerarse, tal y como indica Scheff, como una amplia y variada familia emocional con múltiples manifestaciones que comparten una naturaleza común. El desconcierto, la turbación y el embarazo, o la "pérdida de cara», como pusiera de manifiesto Goffman en sus trabajos acerca de la interacción social en la vida cotidiana (Goffman, 1956), forman parte de la familia emocional de la vergüenza. El ridículo, la humillación, los sentimientos que emergen cuando cometemos errores, o cuando aparecemos como tontos o incapaces ante los ojos de los demás, también forman parte de este conglomerado. Las emociones vinculadas a la pérdida del honor o de la dignidad, el bochorno, el pudor, la degradación o la timidez, constituyen otras tantas expresiones de la vergüenza. En la mayor parte de los casos, sin embargo, no reconocemos estas situaciones como vergonzosas, sino que eludimos o reprimimos la calificación verbal explícita mediante el uso de determinadas metáforas o metonimias. Por ejemplo, podemos referirnos a la vergüenza señalando lo penoso de la situa- 
ción, o de otras múltiples maneras. Así, cuando oímos decir: «pasó un mal rato", "quedé como un idiota», "qué mal trago", "se produjo una situación embarazosa», "fue muy duro para él», "pensé morirme» o "salió con las orejas gachas», con toda probabilidad se alude a un sentimiento de vergüenza.

Desde la perspectiva teórica de Scheff, como ya hemos dicho, la vergüenza señala el estado del vínculo social. En todas sus situaciones típicas siempre existe una exposición pública del yo, real o imaginada, en la que está en juego la imagen de la persona. Este deterioro de la imagen no afecta a un aspecto particular, sino a la persona en su conjunto. Además, en tales situaciones, el yo siempre aparece en una posición de debilidad frente a los otros. La vergüenza, por último, como señalan muchas de sus metáforas, es un sentimiento muy doloroso, pues la supervivencia del ser humano está condicionada, desde su más tierna infancia, al establecimiento de vínculos sociales, a su sociabilidad (Retzinger, 1991). Y esto es lo que explica tanto su importancia como la fuerza de sus imperativos conductuales.

Así, en nuestro relato del accidente de coche pueden oírse ecos de la vergüenza siempre que el joven conductor se expone a la mirada pública con potenciales evaluaciones negativas. Cuando se excluye la pena de cárcel, y se afirma que este castigo sólo sería producto de la venganza (3), el relato afirma que no se trata de culpa. Sin embargo, cuando el perdón pasa por un auténtico arrepentimiento, el relato está refiriendo la vergüenza. Esto es, exige una restauración, no una restitución, como puede verse en el siguiente párrafo: /«El tribunal está convencido de que Jason Rausch [el conductor] está verdaderamente arrepentido y que, desde el día que sucedió esto, no ha dejado de pensar sobre lo ocurrido y sobre su responsabilidad»/ (4). Cuando el relato señala / $Y$ tendrá que vivir con esto el resto de su vida. Sabe que ha sido a sus amigos a quienes hirió»/ (4); así como cuando refiere que /Keller afirmó que cree que la sentencia fue «razonable y justa, emitida por un juez que lo tuvo todo en cuenta»/ (9), añadiendo: / No creo que [Rausch] pueda volver a ser feliz. Tendrá que vivir con esto el resto de su vida» (10), aparecen claramente los ecos del relato bíblico de la vergüenza. Jason Rausch ha debido probar alguna fruta prohibida. La cuestión clave en este punto es: ¿de qué tiene que arrepentirse el conductor? Si no se ha determinado ninguna responsabilidad en el acontecimiento, ni tampoco ninguna intencionalidad, sino un mero error que condujo a un accidente, ¿por qué debía pensar en "esto" durante todos los días desde que sucedió el accidente? ¿Por qué tendrá que vivir con "esto" durante el resto de su vida? ¿Qué es «esto» con lo que Rausch tendrá que vivir? El «esto» es la vergüenza de haber cometido un error. ¿Por qué Jason Rausch ya nunca podrá ser feliz? Por la vergüenza.

De hecho, el verdadero castigo impuesto por el «justo» juez no es otro que /250 horas de servicio comunitario, parte de las cuales tiene que dedicarlas a hablar a los jóvenes sobre los riesgos de la conducción temeraria/ (2). Al menos cien horas deben ser dedicadas a / «charlar y hablar con otros grupos de adolescentes que necesitan una lección de lo que puede ocurrir en un accidente 
como el suyo, incluso sin haber bebido/ (6). Es decir, el juez le castiga a una exposición pública, necesariamente negativa. Le castiga a pasar vergüenza mostrando su error, su incapacidad de control y su deficiencia. Una dolorosa humillación, como el mismo relato se ocupa de subrayar. /Keller [la abogada defensora] anticipa que a su cliente le será emocionalmente difícil soportar las charlas a estudiantes de enseñanza secundaria ordenadas por el juzgado/ (21). / "Va a ser realmente duro para él», dijo ella. "Es cuestión de revivir esto. No es algo que vaya a tomar a la ligera. Cada vez que se dirija a un grupo, tendrá que hacerse de acero para rememorar los acontecimientos, que son horrorosos»/ (22). Aquí el rasgo mortificador de la vergüenza, al que aludiera Cooley, es evidente. Si la vivencia compartida es el mayor bien, la separación social, el destierro de la ciudad, como bien señaló Sócrates, es el mayor de los castigos.

\section{La preocupación}

Si la cadena emocional del relato comenzaba con la atribución de horror al propio acontecimiento, y seguía, según hemos visto, con la proyección de vergüenza sobre el conductor del vehículo, la cadena emocional termina con el intento comunicativo de generalizar un nuevo sentimiento, la preocupación. En principio, es importante notar que la cadena no sólo contiene tres distintas emociones, sino que cada una de ellas se proyecta sobre diferentes objetos: sobre el acontecimiento en sí, sobre el conductor y sobre la población en general, especialmente sobre los padres. En segundo término, es importante señalar que si bien la preocupación aparece con una menor carga emocional, al menos comparada con el horror o la vergüenza analizados anteriormente, esto no le resta un ápice de su importancia. Esta emoción es menos intensa pero más duradera, y constituye el verdadero enlace pragmático, como veremos en el siguiente epígrafe, entre las explosiones emocionales, súbitas pero efímeras, y las modificaciones vitales del sistema social.

La preocupación puede entenderse como «una cadena de pensamientos e imágenes, relativamente incontrolable, cargada negativamente en lo afectivo; implica un esfuerzo por aplicar un proceso mental de solución de problemas a un asunto cuyo resultado es incierto, pero que contiene la posibilidad de uno o más resultados negativos; consecuentemente, la preocupación está muy relacionada con los procesos de miedo" (Borkovec, 1994: 7). De la definición pueden deducirse algunas de sus más importantes características, unas vinculadas a su naturaleza emocional y otras a su naturaleza cognitiva.

La preocupación está asociada a sentimientos de miedo, pero se trata de un miedo a "algo" indefinido en uno o varios de sus aspectos fundamentales. La indefinición está normalmente asociada a la incertidumbre. Desconocemos si el hecho causa de la preocupación acaecerá o no, desconocemos la probabilidad de su acaecimiento, así como el lugar y el instante en el que nos puede sobrevenir. En este contexto de incertidumbre y de ambigüedad, las posibilida- 
des abiertas a la definición subjetiva de la realidad son muy amplias, y esto determina el que en muchos casos la preocupación adquiera un carácter obsesivo, generando así altos niveles de desasosiego. Además, esta ambigüedad en la fuente del miedo produce otra no menos importante. En la preocupación desconocemos la forma exacta de afrontar el peligro, lo que conduce a una incontrolable consideración de escenarios y de soluciones hipotéticas, que en ningún caso determinan una conducta instrumental concreta. La preocupación constituye una especie de ansiedad que se incrementa cuanto menor es la confianza del sujeto para afrontar los peligros, sean reales o imaginados. Por este motivo la preocupación puede alimentarse a sí misma, identificando cualquier contingencia o incertidumbre, por improbable que sea, con un peligro seguro. En suma, este sentimiento está vinculado, primero, a nuestra capacidad de control; segundo, a nuestra sensibilidad para resistir la contingencia, y tercero, a la magnificación de los resultados negativos que puedan esperarse. En la medida en que esta visión del mundo se imponga a un sujeto o a una cultura, resulta más que probable su asociación con estados depresivos.

El sentimiento de preocupación, además de sus componentes emocionales, contiene componentes y funciones cognitivos. En general se trata, según se la ha definido, de un proceso mental de resolución de problemas, proceso que puede presentarse en dos formas alternativas: una "normal», que implica un pre-ocuparse de, y otra patológica, tal y como ha sido descrita en el párrafo anterior. Desde el punto de vista perceptivo, la preocupación establece una clara selectividad de la mirada, pone en alerta el sistema focalizándolo exclusivamente sobre el asunto que nos preocupa. Esto es, estrecha el campo de atención y mantiene viva la alerta sobre cualquier modificación del campo enfocado. El estar alerta, a su vez, genera desasosiego, pero aviva la conciencia sobre cualquier indicio de peligro. Sin embargo, dado el estrechamiento de foco que motiva, la preocupación puede ser también disfuncional en términos cognitivos, pues al mismo tiempo que nos mantenemos alerta en un campo, perdemos el foco sobre otros ámbitos de la realidad. La selectividad del foco, más allá de su disfuncionalidad cognitiva, expresa también una selectividad valorativa. Es decir, nos preocupamos de aquello que valoramos.

En nuestro relato del accidente de coche, el sentimiento de preocupación juega un papel clave, no sólo como supuesta causa del accidente, sino también como función pragmática del sentido del relato. Así, es evidente la "misión preocupadora» del servicio a la comunidad impuesto al conductor para llevar a otros jóvenes el mensaje /sobre los riesgos de una conducción temeraria/ (2). Como se ve, el mensaje es bastante ambiguo, aunque taxativo: hay que preocuparse, prestar atención, cuando se conduce. En caso contrario puede sobrevenir el acontecimiento fatal. Este mensaje se edita en diversas partes del relato, pese a que sólo se ha demostrado la existencia de un error, pero no la falta de atención o despreocupación del conductor.

También el caso sirve para estimular otros tipos de preocupaciones, siguiendo la estela de las responsabilidades de todos los sujetos implicados en 
el suceso. Por ejemplo, estimula la preocupación de los padres sobre los hijos. /Dickey [el juez] habló sobre la responsabilidad que los padres tienen de vigilar de cerca las actividades de adolescentes como los que se montaron en un Chevrolet Blazer el pasado 23 de mayo con Rausch al volante» (5). Para que no quede el menor rastro de duda sobre la facticidad del peligro, la noticia relata cómo Vickie Bridgman /enseñó a Rausch fotos de su hijo Donny vivo y muerto/ (11). Centrándose en el aspecto funcional de la preocupación, otra madre dice: /Creo que hablar a los adolescentes sobre el hecho de ser el conductor designado es importante/ (20). /Vickie Bridgman dijo que su hijo "nunca debió haber bebido»/ (24). Su hijo, desde luego, no conducía, pero con ello se muestra el riesgo y se proyecta la preocupación incluso en los casos en que el conductor no bebe pero los acompañantes sí. También preocupación, y responsabilidad, para los policías, citando a aquel que detuvo el coche el día del accidente, vio las latas de cerveza en su interior, obligó a los jóvenes a vaciarlas, pero luego /les dejó marchar/ (25).

Más allá de estos comentarios, diseminados a lo largo del texto, interesa destacar la escena final del relato, allí donde se dice la última palabra. Curioso, en primer lugar, que sea el padre del conductor quien las pronuncie, pese a que en el relato sólo aparecen las madres. /El padre de Rausch, Manny Hernández, habló brevemente con los reporteros y dijo que esperaba que la situación sirviera como una llamada de atención para todos los padres, porque "esto le podría pasar a su familia»/ (30). Éste es el mensaje final, mensaje de preocupación (hay que estar alerta), de incertidumbre (puede pasar) y de la generalización de la amenaza del peligro y de la ansiedad (a tu familia). El "esto» citado, en su genial ambigüedad, podría aplicarse tanto al horror de la muerte como a la vergüenza del error, y quizás sea este doble vínculo el que ofrezca la única interpretación correcta, el que ofrezca el verdadero e íntimo sentido de este magnífico relato de un accidente de coche.

\section{b) EL CONTENIDO CAUSAL: CAUSAS, RESPONSABILIDADES Y CULPAS}

El sentido comunicativo que porta la cadena emocional de este artículo de prensa, así como su función pragmática, no pueden ser cabalmente comprendidos sin una previa consideración de su trama causal. Para entender este contenido es necesario reflexionar, en primer término, sobre el problema de la atribución causal y, en segundo término, sobre la distinción entre causas, responsabilidades y culpas.

El nudo de la trama causal del artículo se encuentra en la propia calificación del evento como "accidente», y sólo una deconstrucción de tal atributo puede revelar las esencias de su sentido. La calificación del evento como accidente es ya en sí mismo un hecho, es decir, algo construido, una elaborada descripción del sujeto que percibe, descripción que comporta un modelo causal subyacente. En síntesis, podríamos decir que el ser «accidente» comporta una 
exoneración de la culpa que vale tanto para el conductor como para el sistema de movilidad, o, dicho de otra manera, que vale tanto para el individuo como para el sistema social. La denominación de "accidente» constituye el modo más común de definir un "suceso" de una forma causalmente no problemática (Bucher, 1957: 468). Consideramos accidente a un evento cuando es baja la probabilidad de su ocurrencia y/o cuando tal ocurrencia es atribuida al azar. Sin embargo, siguiendo los argumentos de Collins, esto se produce cuando desconocemos las causas, o cuando el hecho es producido por la concurrencia de dos cadenas causales independientes, que es precisamente lo indicado por el término casualidad. En palabras de Collins, "Casualidad”, por tanto, no significa la ausencia de causalidad»(Collins, 1984: 332).

Parece evidente, aunque sea necesario recordarlo, que no a todos los "hechos» aplicamos un modelo causal determinado. Esta aplicación, en términos de Luhmann, es en sí misma ya una selección. Por ejemplo, si un suceso acontece tan sólo una vez, quizás nos baste con decir que ha sido un accidente. $\mathrm{Su}$ improbabilidad, por muy funestas que sean sus consecuencias, convierte en irrelevante la investigación de sus causas. Algo similar ocurre con la conducta humana, pues sólo a una pequeña parte de nuestras acciones le atribuimos, o le son atribuidos por otros, determinados «motivos». Dado que en la mayor parte de los casos ni siquiera se plantea el asunto, «esta imputación y aseveración de motivos por parte de los actores es en sí mismo un fenómeno social que debe ser explicado" (Mills, 1940: 904). Desde la perspectiva de Luhmann, que implica un modelo muy complejo de causalidad sistémica, toda atribución se apoya en una simplificación; aún más, el autor llega a afirmar que «el causante es cualquiera al que uno puede pillar». De entre las múltiples causas, responsabilidades y culpas que están conectadas a un evento, uno debe necesariamente establecer una selección, que por fuerza habrá de considerarse en gran medida arbitraria. En una afirmación similar a la de C. W. Mills, Luhmann señala que «metodológicamente, esto significa que el punto de partida tiene que ser la observación de los sistemas que se autoobservan, y no la asumida ontología de la causalidad» (Luhmann, 1986: 9).

En suma, el ser accidental del evento es una atribución social que debe ser en sí misma analizada. En nuestro relato del accidente de coche, el calificativo parece un tanto forzado si consideramos que cada año el sistema de movilidad mecánica del automóvil genera decenas de miles de accidentes y miles de muertos en cualquier país desarrollado. Aplicando un modelo causal probabilístico, la supuesta "accidentalidad" se transmuta en "esencialidad" del sistema. El accidente de coche es consustancial o esencial al sistema de movilidad. Ahora bien, una imputación de este tipo entraría en franca contradicción con el hecho de que el sistema de movilidad mecánica basado en el automóvil es absolutamente necesario para el mantenimiento de la sociedad moderna. Constituye un modo de ser en el espacio consustancial a su naturaleza e imprescindible para sus desempeños funcionales (Bericat, 1994). Y entonces, como diría Luhmann, a este causante no se le puede pillar, por lo que hay que 
orientar la atribución hacia otro lado; por ejemplo, hacia el conductor, hacia el sujeto individual.

De hecho, nuestro relato ni siquiera menciona disputa alguna acerca de una causa sistémica o de una causa individual. Tanto la batalla legal como el debate comunitario, tal como se señaló anteriormente, se centran en el individuo, en la atribución de vergüenza o de culpa. El relato, ahora ya lo sabemos, debatiendo sobre la culpabilidad del sujeto, y calificando al evento como accidente, exonera de toda culpabilidad al sistema. Se pasa de un modelo causal probabilístico a un modelo causal mecánico que analiza el evento concreto en su singularidad fenoménica. En este punto, siguiendo los argumentos que Rue Bucher aplicó a un caso de tres accidentes consecutivos de avión que se produjeron en una misma ciudad (Bucher, 1957), distinguiremos entre culpa y responsabilidad. Para que exista atribución de culpa, es necesario añadir dos condiciones que afecten a los sujetos considerados: una, al responsable se le tiene que atribuir intencionalidad; y dos, el responsable ha de ser visto como una persona que viola los estándares morales, como estando en oposición a los valores compartidos por la comunidad.

Desde esta consideración, es obvio que al joven Jason Rausch no se le puede considerar culpable. Primero, no se pudo mostrar intencionalidad en su conducta. Segundo, en ningún caso manifiesta oposición a los valores comunitarios. Antes al contrario, el relato contiene expresivas manifestaciones acerca del arrepentimiento del conductor y, lo que es más importante, acerca de la autenticidad de ese arrepentimiento ${ }^{8}$. Sólo la madre del joven muerto se atreve a ponerlo en duda, y le imputa culpabilidad (ver párrafos 4, 13, 14, 20, 26 y 27). Pero ni un ápice de culpabilidad se pudo mostrar en el juicio. Ni siquiera pudieron encontrarse razones que permitieran al juez retirarle el carnet de conducir (párrafo 8). Y, sin embargo, el relato, señalando en su propio titular el hecho de que el joven se ha librado de la cárcel, es decir, que ha estado a punto de ir a la cárcel, parece aludir a una cuasi-culpabilidad. Quizás el titular periodístico intente satisfacer así las opiniones de los dos bandos de la comunidad, pero éste no puede ser el único motivo de tal presentación.

El verdadero origen está en el concepto de responsabilidad. Siguiendo de nuevo los argumentos de Bucher, diremos que más allá de considerar un «evento" en tanto "hecho", causado o no de una determinada manera, el relato contempla el evento en tanto "acto", lo que implica ya un planteamiento de responsabilidad personal en la acción. Para atribuir responsabilidad se requieren dos condiciones: una, un determinado modelo causal, que en nuestro relato se concreta en la exoneración del sistema, o negación de la causa probabilística; y dos, la creencia de que es posible hacer algo para evitar futuros sucesos de este tipo. Desde esta perspectiva, como señala Bucher en su investigación, "no era el agente causante del suceso lo que determinaba la responsabilidad, sino la

8 Para una consideración de la importancia de la autenticidad en el arrepentimiento, ver Th. Scheff (1997), «Deconstructing Rage» (inédito) y Scheff (1994). 
capacidad de hacer algo para prevenir su recurrencia» futura (Bucher, 1957: 471). Es decir, la responsabilidad pervierte el orden temporal de causa-efecto (la causa debe preceder al efecto para ser tal), y establece un juego teleológico del "como si», como si el sujeto fuera el causante porque no hay otro causante a quien pillar. De entre todas las causas eficientes del evento, se establece socialmente una simplificación, enfocando tan sólo la falta de control del conductor, su descuidada conducta y el exceso de velocidad.

La culpa reside en el error, en la escasa atención, en el insuficiente control del conductor al volante (ver párrafos 2, 3, 5, 6, 8 y 20). Una imputación ambigua que es indemostrable, pero que al mismo tiempo se puede imputar a cualquier conductor de automóvil que tenga un accidente. Dado que no hay intencionalidad, dado que el individuo no está en situación de control, al caso corresponde la proyección de vergüenza. No es malvado, es incapaz. Esta vergüenza también puede proyectarse por el incumplimiento ritual de las normas. Así sucede cuando los conductores, como Jason Rausch, violan el límite de velocidad, la "fruta prohibida» del sistema de movilidad. En el relato no se demuestra vínculo causal alguno entre circular por encima del límite y el accidente concreto. Sin embargo, todos tienen interés en transformar una causa probabilística (a mayor velocidad, más probabilidad de accidentes) en una causa mecánica (ver párrafos 1,20 y 28). Y esto por dos razones, por resentimiento y por interés. La velocidad, en virtud de su límite legal, es la fruta prohibida del sistema por cuanto aquello que promete el automóvil, es decir, rápidos desplazamientos espaciales, es negado por el límite. Y si de esa fruta no puedo comer yo, no me gusta que coma nadie. En segundo lugar, dando por cierta la relación probabilística entre velocidad y accidentalidad, estoy interesado en que haya menos accidentes, pues de lo contrario esto podría conllevar nuevos descensos en los límites de velocidad. Con cada descenso del límite, el sistema de movilidad se deslegitima. Con cada muerte habida en accidentes, el sistema también se deslegitima. Las sociedades que se trasladan por el espacio en automóvil, como bien puede observarse en la cultura americana, disfrutan de un sistema de movilidad a "medio pedal». Para pisar el acelerador hay que evitar toda muerte, y ello comporta buscar responsabilidad, más allá de la causalidad, allí donde sea posible. Si ésta se encuentra en el conductor, el modo de atribución deslegitima y culpabiliza, o al menos avergüenza, al individuo, dejando así intacto el orgullo del sistema. Como dijimos al principio de este apartado, toda una "trama» causal. De todo el relato un hecho parece claro, como pone de manifiesto la madre del joven muerto enseñando dos fotos, una de su hijo vivo y otra de su hijo muerto, al joven conductor (11): la vergüenza que en todo caso proyecta la muerte.

\section{LA VIVENCIA EMOCIONAL EN LA SOCIEDAD DEL RIESGO}

Los medios de comunicación funcionan como una linterna en un cuarto oscuro. La linterna proyecta, en cada instante, un haz lumínico sobre algún 
objeto o sobre las paredes del cuarto. Entretanto, el resto de la estancia queda en la más absoluta oscuridad, es decir, únicamente podemos iluminar a la vez una de las múltiples caras del objeto. Podemos mover la linterna, esto es, tenemos la posibilidad de jugar con el espacio y con el tiempo, y así ir descubriendo los diferentes objetos contenidos entre sus paredes. Este movimiento de la linterna teje una narración visual con la que nos formamos una idea de la realidad del cuarto, de los instrumentos que en él podemos hallar, así como de los obstáculos con los que podemos tropezar.

La metáfora de la linterna, sin duda, es demasiado simple para entender el proceso de comunicación social, pero en ningún caso es una metáfora ingenua. Por ejemplo, basta con que admitamos la existencia de múltiples linternas en un mismo cuarto, cada una de ellas dirigida por diferentes personas, para que la metáfora se complique. Si además, por ejemplo, postulamos que la potencia de las linternas es diferente, el análisis de las luces y de las sombras puede ser realmente complejo. Como las linternas se mueven, las narraciones visuales se entrecruzan en el espacio y en el tiempo. También podemos preguntarnos si todos los individuos del cuarto tienen o no tienen linterna, y de qué potencia. También podemos inquirir, finalmente, por qué enfocan a unos objetos y no a otros, es decir, qué y quién determina la dirección del haz.

En todo caso, esta metáfora nos será útil para comprender la lógica emocional desvelada en nuestro relato. Cada vez que la linterna cambia de foco muestra un objeto, en nuestro caso una muerte. Toda muerte produce horror, y produce horror en todos. El horror, según vimos, comporta una carga moral que activa la búsqueda de responsables. La linterna ahora pasa a iluminar al responsable, y todos los ocupantes de la estancia, menos uno, pueden observarlo. A su vez, el responsable se sabe visto, pues él es el único que no ve. Para evitar la luz, ahora tan molesta, se tapa la cara con las manos o entorna los ojos. La luz tiene efectos aislantes. La luz, por tanto, tiene efectos amenazantes. Cualquiera, llegado el caso, podría ser en el futuro el objeto a iluminar. Esto introduce la incertidumbre y con ella el desasosiego, la preocupación. El instante del horror se narra junto al instante de la vergüenza, y por este motivo están en el tiempo, tienen su límite; pero la preocupación es mucho más duradera, introduce un cambio en la estructura cognitiva, valorativa y emotiva de los individuos.

El argumento clave es la necesidad de estudiar cadenas emocionales. Desde un punto de vista perceptivo, en nuestra cadena emocional existen dos instantes reales, el del horror y el de la vergüenza, y un tercer instante hipotético, el de la preocupación. Paradójicamente, los dos primeros desaparecen, mientras que la vivencia de la preocupación perdura en el tiempo. Prescindir de este efecto constituye uno de los más graves errores que se cometen al considerar el ámbito emocional. Muchos reducen lo emocional a estos instantes emocionalmente intensos, sin apenas preguntarse qué queda de ellos o, mejor dicho, qué queda tras ellos. Tras el instante del horror público atribuido al evento, y tras la vergüenza privada atribuida al responsable, se produce la preocupación en todos. 
Una emoción de baja intensidad, perdurable en el tiempo y difundida por el espacio social. Vistas así las cosas, el horror y la vergüenza son meros instrumentos de la preocupación, aunque cada tipo de preocupación lleve las marcas de las emociones que le dieron origen.

Este mismo error se detecta en algunas consideraciones típicas acerca de los medios de comunicación. Algunos creen que la linterna comunicativa, para ser eficaz, ha de estar permanentemente enfocando un objeto, y desde esta posición critican la volubilidad de la agenda de los medios. Sin embargo, como hemos visto, no es necesario mantener eternamente la mirada para provocar efectos emocionales duraderos. Una fijación excesiva de la agenda constituye un peligro en un sistema social complejo, pues la linterna tiene que iluminar muchos aspectos de este sistema, tiene que provocar muchas sugerencias y establecer adecuados vínculos pragmáticos con el sistema de actividad. Más allá del éxito de sus propuestas particulares, es decir, de la adopción de medidas políticas subsecuentes (Birkland, 1997), es obvio que el enfoque y la atención comunicativa se rigen por una lógica vinculada al proceso de autoproducción del sistema social (Luhmann, 1995), más allá del interés intrínseco de los eventos y personas particulares con los que se constituyen las noticias, meros materiales necesarios para la producción de los relatos. Una vez que la funcionalidad del evento en tanto expresión comunicativa está saturada, su noticiabilidad se agota.

Es obvio que la cadena de horror, vergüenza y preocupación revelada en nuestro relato no es la única estructura emocional con la que funcionan los mensajes. Nuestro objetivo, como ya hemos señalado, era mostrar, mediante un análisis microscópico de la expresión comunicativa, la presencia emocional. En el mismo periódico investigado se revelaron una amplia variedad de estructuras, no comentadas aquí por evidentes razones de espacio. Si la investigación, por otra parte, hubiera analizado la prensa del corazón, la deportiva, los reality shows o la misma publicidad, a buen seguro hubieran aparecido otras diferentes cadenas emocionales, así como otros vínculos funcionales y pragmáticos asociados. Por este motivo es importante localizar en el universo de la mass-mediación el lugar donde se inserta el relato del accidente de coche. Su lugar es el de un periódico de los catalogados como "serios», y concretamente el cuadernillo principal, esto es, el que se ocupa, en sentido genérico, de la «política». Esta precisa posición, como veremos ahora, determina su funcionalidad social.

El noúmeno de lo político, ubicado detrás de la pantalla sobre la que se proyectan las sombras chinescas que aparecen en la mass-mediación, queda saturado por dos funciones esenciales: una, la determinación de las metas, objetivos o fines de una comunidad; y dos, la distribución de los recursos a aplicar a una determinada estructura de metas. Una estructura emocional clave de los relatos publicados en un lugar político de la mass-mediación, como es la de horror, vergüenza y preocupación, sólo puede encontrar su verdadero sentido en el contexto político en que ha visto la luz. $\mathrm{O}$, dicho de otra forma, sólo puede tener sentido si se establecen las adecuadas conexiones con la legitimidad 
del sistema, que no es otra cosa que la expresión sistémica o la aquiescencia intersubjetiva de la estructura de metas y de la aplicación de recursos a las mismas. Acotado de esta manera el ámbito en el que ha de encontrar su significación y sentido, podríamos decir, a falta de las oportunas y necesarias investigaciones cuantitativas subsecuentes que puedan demostrar sus grados de validez externa (Bericat, 1998), que esta lógica desvelada en el relato del accidente de coche constituye no una lógica más entre otras muchas posibles, sino una lógica emocional clave en los mecanismos de legitimación politica de las sociedades posmodernas, sociedades que han sido catalogadas también por reconocidos teóricos sociales como sociedades del riesgo.

Es evidente que la cadena emocional analizada no constituye un mecanismo exclusivo de la sociedad del riesgo. La estructura de horror, vergüenza y preocupación es un tipo ideal que podemos encontrar en el desenvolvimiento político de cualquier época. Todo orden debe ser capaz de atraer una atención generalizada para tejer y mantener el umbral de legitimidad, pues no existirá comunidad política alguna sin focos comunes de atención (Dayan y Katz, 1988). De ahí se deduce el hecho de que lo político siempre pretenda monopolizar la atención de la opinión pública, así como saturar en exclusiva la emoción pública o el «clima emocional» de una comunidad (Rivera, 1992). De ahí, también, que toda atención prestada a otras comunicaciones (sean personales, deportivas, económicas o culturales), o toda simple falta de atención, sea catalogada como posible síntoma de falta de legitimidad o de disipación de la energía política del sistema. Como hemos señalado en otro texto, "hoy el control social, frente al viejo modelo del panóptico, donde el poder controlaba observando a los controlados (ojo que ve), se basa en una relación inversa, no en que el súbdito pueda ser visto, sino, muy al contrario, en conseguir que los súbditos vean, en seducirlos para que miren (ojos que miran)» (Bericat, 1996: 116). En este sentido, el horror, el escándalo y la alarma social son muy funcionales para forzar la mirada de todos, para obtener la atención generalizada que la legitimidad del orden político requiere. La expresividad emocional, además, se hace en la sociedad de la infocomunicación más necesaria por la existencia de una amplísima oferta comunicativa, lo que convierte a la atención en un recurso muy escaso por el que compiten desde la publicidad hasta el poder. Esto explica también el hecho de que incluso la prensa "seria» haya incrementado su carga emocional explícita, olvidando su precedente apariencia de "neutralidad afectiva» (Weber, 1992). Para la formación y el mantenimiento de la comunidad política, la audiencia no es un mero problema técnico-comunicativo, sino un recurso imprescindible y esencial.

Nuestra tesis, sin embargo, sostiene que la importancia comunicativa que la muerte adquiere en la sociedad del riesgo, y con ella la cadena emocional descrita, no se debe fundamentalmente a razones técnicas vinculadas al problema de la atención, sino que deriva de los problemas de legitimidad en el capitalismo tardío, especialmente de aquellos vinculados a los procesos de motivación (Habermas, 1975). Aquellos a los que se enfrentan las sociedades modernas 
por el mismo hecho de haber consumado, en gran medida, su proyecto fundacional, esto es, por el hecho que deriva del agotamiento de legitimidad al que ha conducido su propio éxito (Beck, 1997). Deriva de la incapacidad motivacional de los valores modernos originarios (Inglehart, 1997). Deriva, en suma, de la carencia emocional de todo proyecto político de futuro que no sea la resignada y temerosa conservación del presente; del «fin de la historia» (moderna) como estructura vital de la tardomodernidad; de la pérdida de la fe en el progreso, en la ciencia y en el bienestar material que, en este siglo XX, ha palidecido en el marco de una paradoja. En el siglo XX, nos dice Elias, «este progreso es sin duda un hecho, pero para muchas personas ha dejado de ser un ideal»" "Las posibilidades de progreso y de un futuro mejor son hoy mayores que nunca... No obstante, el futuro es decepcionante» (Elias, 1993: 22-30). Ante esta evidente marcha motivacional de la modernidad, ¿de dónde extraer energía motivacional para estos sistemas societarios? La respuesta es: de la muerte como síntoma del mal funcionamiento sistémico, de la preocupación individual por la muerte.

La «linterna» de la sociedad del riesgo salta de una muerte o otra, iluminando el horror y la vergüenza, y dejando tras de sí una estela emocional de preocupación, desasosiego, ansiedad y miedo. Sólo hace falta ver el modo en que los tradicionales «informativos» se han convertido en una ininterrumpida serie de "crónicas de sucesos» más o menos luctuosas. Resulta difícil encontrar una noticia que no esté vinculada, directa o indirectamente, con la muerte: una catástrofe natural en un país lejano; un niño que mata en el colegio a unos compañeros; un taxista que muere a manos de un delincuente; un edificio que se derrumba; un acto racista; un desastre ecológico; una mujer maltratada hasta la agonía; una explosión de gas; un incendio; un escape radiactivo; un atentado terrorista; una guerra; una infección hospitalaria; el fallecimiento de algún famoso; un accidente de coche; el tabaco de la muerte; la amenaza de una innovación tecnológica, o el riesgo de un descubrimiento científico. Incluso la alimentación, fuente de vida, se presenta en tanto muerte, bien transfigurada en anorexia, bien en obesidad como fuente de riesgo.

La tesis que sostenemos nada tiene que ver con las tentadoras y socorridas culpabilizaciones a la prensa o a los medios de comunicación, actualmente tan en boga, como sucede en el caso de la violencia. Los medios son el marco de una experiencia vital propia de la posmodernidad, así como de sus estructuras emocionales. La cultura del miedo, el reinado de la victimización, la sensación de incertidumbre, la aversión al riesgo, la desconfianza en el otro y en el sí mismo, el recelo de la tecnología y de la ciencia no son una invención de los medios, sino la esencia emocional de una época (Furedi, 1997). Si la emoción puede ser entendida como la conciencia del cuerpo, no sólo del cuerpo individual sino también del comunitario, una cuidada consideración de esta conciencia puede mostrarnos nuevas vías para comprender los sistemas socia-

\footnotetext{
9 La cursiva es nuestra.
} 
les, esto es, puede constituir un recurso heurístico clave para la teorización social.

Si a cada época corresponde una peculiar estructura emotiva, y si cada metateorización social contiene la suya, podemos inferir que la plausibilidad académica y social de estas teorías dependerá en gran parte de la sintonía emocional que mantenga con una determinada época en el marco de una estructura social determinada. ¿Acaso alguien puede creer que el "proletariado» siguió a C. Marx por la veracidad cognitiva de sus argumentaciones científico-sociales? ¿Acaso alguien puede creer que los desvaríos lógicos del pensamiento positivo de A. Comte podían sostenerse sin la transmisión propia de un sentimiento positivo acorde con la naciente modernidad? Comte, al concebir el progreso como clave del nuevo sistema social, expresaba íntimamente las metas de esta nueva sociedad moderna, basada en las promesas de la aplicación de la razón (despliegue cultural de la Ilustración y el positivismo) y en su aprovechamiento material (despliegue social de la industrialización). Orden y Progreso expresaban este peculiar tipo de positividad orientada al futuro que constituye la base legitimadora del sistema (Pino, 1990). Todas las metas políticas, y su correspondiente distribución de recursos, como bien supo el proletariado, estaban orientadas en este sentido. En la búsqueda del bienestar económico futuro la modernidad ocultaba los sacrificios laborales del presente. En la búsqueda del orden y de la paz social los estados-nación modernos ocultaban incluso la sangre de los campos de batalla. Progreso supone no sólo una mirada positiva hacia el futuro, que legitima y oculta el dolor, sino también capacidad de control, confianza en las potencialidades humanas. Control del mundo natural, del mundo social y del mundo personal con el que se instituía el sistema de la modernidad en pos del bienestar, de la búsqueda de la verdad y de la libertad.

Pero en torno a la mitad del siglo XX el humor emocional de la modernidad ofrecía ya síntomas radicales de cambio. Por estas fechas se quiebra definitivamente la confianza moderna. La quiebra de la confianza en la ciencia, que ya en la imaginación humana había dado sus frutos, por ejemplo en la ficción literaria de Frankenstein, de Mary Shelley, se hace patente en la explosión de dos bombas atómicas. La confianza en el incremento indefinido del bienestar material también tiene sus límites, en este caso expresados por las restricciones al control humano provenientes del propio mundo natural. Por último, la voluntad de control proyectada sobre el mundo social se quiebra cuando se transfigura en omnímoda voluntad de poder en el régimen Nacionalsocialista, arruinando así la última esperanza moderna. Si fue A. Comte quien mejor expresó en la teoría sociológica el orden de la modernidad como progreso (optimista), y fue T. Parsons quien expresó el orden de la modernidad como destino (satisfecho), sin duda ha sido N. Luhmann quien ha expresado mejor el orden social como incertidumbre o contingencia (ansiosa). Una nueva conciencia de inseguridad sobre el futuro que, en tanto experiencia vital del presente posmoderno, invalida las metas y objetivos de la modernidad como fuentes de legitimidad del sistema. 
Ésta es la nueva sensibilidad que recogen las teorías de la sociedad del riesgo. No haremos aquí, pese a su interés, un análisis del contenido emocional de estas teorías, aunque cualquiera que las conozca podrá detectar el síndrome de pérdida de control que lleva a la preocupación (Beck, 1992, 1996; Luhmann, 1996). La pérdida de la confianza en la ciencia, en el progreso, en la utopía del bienestar económico sin límites, en la obtención de libertad en un mundo demasiado grande y complejo, hacen que la legitimidad política no pueda seguir sustentándose en las viejas metas y valores de la modernidad. La posmodernidad no puede sustentarse en su relación positiva con unos valores que, merced a su éxito, se han vuelto incapaces de alimentar la necesaria motivación política. Pero el sistema sigue demandando legitimidad, pese a las contradicciones. Por lo que esta legitimidad, que ya no puede obtenerse desde la motivación positiva orientada al futuro, se obtiene a través de un renovado pacto hobbesiano sustentado sobre la incertidumbre, la preocupación y el miedo. Las metas que legitiman el orden de la posmodernidad, orden concebido en tanto sociedad del riesgo, sólo pueden ser negativas, se basan en la proyección del temor, no en la búsqueda del bien, sino en la aversión al mal. Las dificultades para encontrar un lugar de consenso se resuelven por el recurso a la evitación de la muerte como paradigma de la aversión al riesgo, clave motivacional del sistema. El miedo a la muerte se restituye como mecanismo legitimador del sistema político, y esto explica el contenido emocional detectado en los medios de comunicación. Ya no hay héroes, ni aventureros, ni revolucionarios; tan sólo víctimas y culpables. La muerte, antes que un don (Derrida, 1995), se concibe como una deuda por la que alguien tiene que pagar (Douglas, 1994). Síndrome de la ambivalencia posmoderna donde coinciden, paradójicamente, un alto grado de control con una mínima conciencia de certidumbre, una máxima esperanza de vida con un intenso temor a la muerte, una menor inseguridad con una obsesiva y permanente conciencia de riesgo.

\section{BIBLIOGRAFÍA}

BECK, U. (1992): Risk society. Towards a New Modernity, Londres, Sage.

- (1996): "Teoría de la sociedad del Riesgo" y "Teoría de la modernización reflexiva», en J. Beriain (comp.), Las consecuencias perversas de la modernidad, Barcelona, Anthropos.

- (1997): "La reinvención de la política: hacia una teoría de la modernización reflexiva», en U. Beck, A. Giddens y S. Lash, Modernización reflexiva. Politica, tradición y estética en el orden social moderno, Madrid, Alianza Editorial.

Bericat Alastuey, E. (1994): Sociología de la movilidad espacial. El sedentarismo nómada, Madrid, CIS.

- (1996): «La sociedad de la Información: tecnología, cultura, sociedad», en REIS, n. ${ }^{\circ} 76$, pp. 99-121.

- (1998): La integración de los métodos cuantitativo y cualitativo en la investigación social. Significado y medida, Barcelona, Ariel.

Birkland, Th. A. (1997): After Disaster. Agenda Setting, Public Policy, and Focusing Events, Washington, Georgetown University Press. 
Borkovec, T. D. (1994): "The nature, functions and origins of worry», en G. C. L. Davey y F. Tallis (eds.), Worrying: perspectives on theory, assessment, and treatment, Chichester, John Willey \& Sons.

Bucher, R. (1957): «Blame and hostility in disaster», en The American Journal of Sociology, vol. LXII, n. ${ }^{\circ}$ 5, pp. 467-475.

CarabaÑA, J., y LAMO DE ESPINOSA, E. (1979): «Resumen y valoración crítica del interaccionismo simbólico", en J. JimÉnez Blanco y C. MoYa VALGAÑon, Teoría sociológica contemporánea, Madrid, Tecnos.

Collins, R. (1984): «Statistics versus words», en R. Collins (ed.), Sociological Theory 1984, San Francisco, Jossey-Bass.

Cooley, Ch. H. (1902): Human Nature and Social Order, Nueva York, Scribner's.

DaveY, G. C. L., y Tallis, F. (eds.) (1994): Worrying; perspectives on theory, assessment, and treatment, Chichester, John Willey \& Sons.

DAYAN, D., y KATZ, E. (1988): «Articulating consensus: the ritual and rhetoric of media events», en J. C. Alexander (ed.), Durkheimian Sociology: Cultural Studies, Nueva York, Cambridge University Press.

Derrida, J. (1995): The Gift of Death, Chicago, The University of Chicago Press.

Dewey, J. (1958): Experience and nature, La Salle, The Open Court Publishing Company.

Douglas, M. (1994): Risk and blame, Londres, Routledge.

Elias, N. (1993): El proceso de la Civilización. Investigaciones sociogenéticas y psicogenéticas, Madrid, Fondo de Cultura Económica.

FUREDI, Frank (1997): Culture of Fear. Risk-taking and the morality o low expectation, Londres, Cassell.

Goffman, E. (1956): «Embarrassment and social organization», en American Journal of Socio$\log y,{ }^{\circ}{ }^{\circ}$ 62, pp. 264-271.

GotTschalk, L. A. Winget, C. N., y Gleser, G. C. (1969a): The Measurement of Psychological states Through the content Analisys of Verbal Behavior, Berkeley, University of California Press.

- (1969b): Manual of Instruccions for Using the Gottschalk-gleser Content Analisys Sacales: Anxiety, Hostility, and Social Alienation-Personal Disorganization, Berkeley, University of California Press.

Habermas, J. (1975): Problemas de legitimación en el capitalismo tardio, Buenos Aires, Amorrortu Editores.

- (1994a): Conciencia moral y acción comunicativa, Barcelona, Península.

- (1994b): Teoría de la acción comunicativa: complementos y estudios previos, Madrid, Cátedra.

Hirschman, A. O. (1999): Las pasiones y los intereses. Argumentos politicos en favor del capitalismo previos a su triunfo, Barcelona, Península.

Luhmann, N. (1989): Ecological Communication, Cambridge, The University of Chicago Press.

- (1995): Social Systems, Stanford, Stanford University Press.

- (1996): «El concepto de riesgo", "El futuro como riesgo" $\mathrm{y}$ "La contingencia como atributo de la sociedad moderna», en J. Beriain (comp.), Las consecuencias perversas de la modernidad, Barcelona, Anthropos.

MacKinnon, N. J. (1994): Symbolic interactionism as affect control, New York, State University of New York Press.

Mills, C. W. (1940): «Situated actions and vocabularies of motives», en American Sociological Review, vol. V, n. ${ }^{\circ}$ 6, pp. 904-914.

Morin, E. (1984): Ciencia con consciencia, Barcelona, Anthropos.

Morris, L. W.; Davis, M. A., y Hutchings, C. H. (1981): "Cognitive and Emotional components of Anxiety: Literature Review and a Revised Worry-Emotionaly Scale», en Journal of Educational Psychology, vol. 73, n. ${ }^{\circ} 4$, pp. 541-555.

PInO, J. del (1990): La teoría sociológica. Un marco de referencia analítico de la modernidad, Madrid, Tecnos.

Retzinger, S. M. (1991): Violent Emotions. Shame and Rage in Marital Quarrels, Newbury Park, Sage. 
Retzinger, S. M. (1995): «Identifying Shame and Anger in Discourse», en American Behavioral Scientist, vol. 38, n. ${ }^{\circ}$, pp. 104-113.

Rivera, J. de (1992), "Emotional Climate: Social Structure and Emotional Dynamics», en International Review of Studies on Emotion, vol. 2, pp. 197-218 (editado por K. T. Strongman).

Scheff, Th. J. (1990): Microsociology. Discourse, Emotion and Social Structure, Chicago, The University of Chicago Press.

- (1997): Emotions, the social bond, and human reality. Part/whole analysis, Cambridge, Cambridge University Press.

Torregrosa Peris, J. R. (1982): «Emociones, sentimientos y estructura social», en J. R. TORREGrosa y E. Crespo, Estudios básicos en Psicología Social, Madrid, Hora, CIS.

Weber, M. (1992): "Max Weber: para una sociología de la prensa», en REIS, n. ${ }^{\circ}$ 57, pp. 251259.

\begin{abstract}
This paper, the result of an empirical research study of a qualitative nature, aims to highlight the lack of interest shown by the social sciences, and particularly sociology, towards the emotional dimension of sociability. This lack of interest, which can be interpreted as the expression of the cultural ethos of modernity itself, cannot be sustained on scientific grounds. Hence the strong emergence in recent years of a line of thought, and a specific field of study, the Sociology of Emotions, the aim of which is to fill this gap.

This research study, based on the key role played by the communicative process in the constitution of social order, as upheld both by symbolic interactionism and N. Luhmann's systems theory, aims to show the social functions fulfilled by the emotional contents present in communication.
\end{abstract}




\section{A N E X O}

LOS ANGELES TIMES, jueves 7 de mayo de 1998

\section{Conductor de 19 años elude la cárcel tras un fatal accidente en Newport Beach}

- Juzgado: el juez afirma que no serviría de nada. Un accidente en el que un joven murió y otros dos resultaron gravemente heridos ha dividido a la comunidad.

Por GREG HERNÁNDEZ

Periodista del Times

1. NEWPORT BEACH.-Para cerrar un caso que ha destrozado amistades y ha dividido amargamente una comunidad, el miércoles, un juez del Tribunal Superior del Condado de Orange libró de una sentencia de cárcel a Jason Rausch, de 19 años de edad, por conducir con exceso de velocidad y provocar un accidente en el que murió un antiguo compañero de clase suyo y causó graves lesiones cerebrales a otros dos jóvenes.

2. El graduado del Colegio Harbor de Newport fue sentenciado a tres años de libertad condicional, a un máximo de 1.000 dólares de multa, a una indemnización a las familias de las víctimas y a 250 horas de servicio comunitario, parte de las cuales tiene que dedicarlas a hablar a los jóvenes sobre los riesgos de la conducción temeraria.

3. El juez Everett Dickey, que declaró a Rausch culpable de un delito de homicidio no premeditado con vehículo en febrero, afirmó que pensaba que una sentencia de cárcel no tendría otro propósito que la venganza emocional.

4. «El tribunal está convencido de que Jason Rausch está verdaderamente arrepentido y que, desde el día que sucedió esto, no ha dejado de pensar sobre lo ocurrido y sobre su responsabilidad», afirmó Dickey. "Y tendrá que vivir con esto el resto de su vida. Sabe que ha sido a sus amigos a quienes hirió».

5. Dickey habló sobre la responsabilidad que los padres tienen de vigilar de cerca las actividades de adolescentes como los que se montaron en un Chevrolet Blazer el pasado 23 de mayo con Rausch al volante. El vehículo volcó y se estrelló en una curva cerrada de Irvine Avenue, arrojando ocho adolescentes sobre la calzada. Esa noche, Rausch había sido designado conductor, y no había bebido. Aun así, el accidente ha provocado una encarnizada batalla legal y un debate sobre su culpabilidad en la comunidad.

6. Dickey ordenó que Rausch dedicara al menos cien horas de ser- 
vicio comunitario a «charlar y hablar con otros grupos de adolescentes que necesitan una lección sobre lo que puede ocurrir en un accidente como el suyo, incluso sin haber bebido".

7. En el accidente murió Donny Bridgman, de 18 años, propietario del Blazer. Amanda Arthur, de 18 años, entró en coma y despertó once semanas más tarde. Arthur, a quien el otoño pasado nombraron reina de las graduadas del colegio, padece una lesión cerebral posiblemente irreversible. Otro estudiante, Danny Townsend, se está recuperando de otra lesión cerebral.

8. El representante del Fiscal General, Jim Dutton, ha pedido un período de seis meses de cárcel para Rausch y que se le retire el permiso de conducir como condición de la libertad condicional. Dickey replicó que, como la condena de Rausch no incluía negligencia grave ni intoxicación, no pudo encontrar ni un artículo del código legal que le permitiese retirarle el permiso, revocado en septiembre por el Departamento de Vehículos a Motor a causa del accidente.

9. La abogada de la defensa, Jennifer Keller, señaló que no estaba segura de cuánto iba a durar la revocación, y que era una cuestión que aún estaba por resolver. Keller afirmó que cree que la sentencia fue «razonable y justa, emitida por un juez que lo tuvo todo en cuenta».

10. Pero Keller añadió: «No creo que [Rausch] pueda volver a ser feliz. Tendrá que vivir con esto el resto de su vida».

11. Vickie Bridgman, quien el martes enseño a Rausch fotos de su hijo Donny vivo y muerto, dijo que no creía que la sentencia fuera justa, pero que era «lo que había estado esperando durante mucho, mucho tiempo. No ha sido una sorpresa para mí».

12. «No creo que mi familia haya recibido un trato justo", dijo ella.

13. Bridgman afirmó que aunque Rausch fue a verla tras el accidente y le dijo que lo sentía, la visita estuvo llena de "falsas excusas». No cree que el adolescente se haya sentido en ningún momento responsable del accidente, algo que alimenta su amargura.

14. «Si admites tus errores, llevas una vida provechosa y haces cosas productivas, entonces te puedo perdonar. $\mathrm{Y}$ eso es lo que le dije». "Y esto no es lo que ha ocurrido".

15. Diana Townsend, la madre de Danny Townsend, parecía aliviada de que el juicio terminara.

16. «Me alegro que haya terminado», dijo. "Jason seguirá su vida, y esperemos que Danny se cure y siga su vida».

17. Esta semana, Bridgman y Townsend dijeron que todavía estaban considerando si iniciar una demanda civil contra Rausch.

18. Nada podía estar más lejos de la mente de Chris Maese, la madre de Amanda Arthur, quien se está preparando para volver al colegio Harbor de Newport en régi- 
men limitado a partir del viernes y pasar allí al menos parte de su último año en el campus. Amanda se va a matricular como estudiante en régimen especial, y asistirá a clases matutinas tres días a la semana durante el resto del año, dijo su madre.

19. «Mandy quiere desesperadamente volver a la escuela», afirmó Maese. «Si realmente aprenderá algo, no lo sé, pero será bueno para su ánimo y su moral».

20. Maese dijo que creía que la sentencia de Rausch era justa. "Creo que es magnífica», señaló Maese. "Él ha hecho mucho por la recuperación de Amanda. Fue un error. Supimos que conducía demasiado deprisa. Pero no creemos que deba ir a la cárcel por ello. Creo que sí se ha hecho justicia. Pienso que la sentencia fue perfecta. Creo que hablar a los adolescentes sobre el hecho de ser conductor designado es importante».

21. Keller anticipa que a su cliente le será emocionalmente difícil soportar las charlas a estudiantes de enseñanza secundaria ordenadas por el juzgado. Pero dijo que está dispuesto a hacerlo, del mismo modo que a cumplir tiempo en prisión si eso fuese lo que tenía que hacer.

22. «Va a ser verdaderamente duro para él», dijo ella. "Es una cuestión de revivir esto. No es algo que vaya a tomar a la ligera. Cada vez que se dirija a un grupo, tendrá que hacerse de acero para rememorar estos acontecimientos, que son horrorosos».
23. La madre de Rausch, Leslie Backstrom, testificó al principio de la semana y dijo que su hijo pensó en el suicidio tras el accidente y que todavía sufre pesadillas. Dijo que la fama del accidente le había causado dificultades para encontrar un trabajo y que los procedimientos legales le habían hecho abandonar al menos dos cursos universitarios.

24. El accidente ha provocado un largo debate sobre las gamberradas festivas de los adolescentes, una cuestión que el jueves estaba en la mente de muchos en el juzgado, incluida Vickie Bridgman, quien dijo que su hijo «nunca debió haber bebido» esa noche.

25. Un ayudante del comisario del Condado de Orange había detenido al Blazer antes del accidente y había hecho preguntas a Rausch. El ayudante miró dentro del coche y vio latas de cerveza. Hizo que los adolescentes tiraran la cerveza y luego les dejó marchar. Los adolescentes fueron a una bodega y utilizaron una identificación falsa para comprar más cerveza.

26. Pero Bridgman sigue culpando del accidente a Rausch, el conductor designado, no a su hijo ni a ningún otro de los que iban en el Blazer.

27. «Es como el piloto de un avión», dijo. "¿Echaríamos la culpa a los pasajeros por un error del piloto?».

28. La noche del accidente, Rausch conducía por primera vez el Blazer de Donny Bridgman, un 
hecho que, según el juez, contribuyó al accidente. Se discutió la velocidad a la que iba Rausch esa noche: la acusación afirmaba que conducía a más de 60 millas por hora, mientras la defensa mantenía que viajaba a 44 millas por hora aproximadamente. El límite de velocidad en la carretera era de 35 millas por hora.

29. Rausch, que actualmente es estudiante del Orange Coast College, apenas mostró reacción alguna cuando el juez le impuso la sentencia. Finalmente, se levantó y abrazó a su madre; luego salió lentamente de la sala, donde se enfrentó a una multitud de cámaras.

30. El padre de Rausch, Manny Hernández, habló brevemente con los reporteros y dijo que esperaba que la situación sirviera como una llamada de atención para todos los padres, porque «esto le podría pasar a su familia».

El corresponsal del Times, Hope Hamashige, colaboró en este artículo. 